\title{
PEER REVIEWED ABSTRACT SUBMITTED TO THE COLLEGE OF HEALTH SCIENCES, OSUN STATE UNIVERSITY ANNUAL SCIENTIFIC CONFERENCE, JUNE 15-19, 2020.
}

\section{ABSTRACT - CHS/2020/01 \\ Assessment of risk factors associated with drug resistant-tuberculosis among patients on dots treatment for tuberculosis in Ibadan, Oyo State}

\author{
*Akinleye, C.A. ${ }^{1}$, Onabule, A. ${ }^{2}$, Oyekale, A.O. ${ }^{3}$, Akindele, M.O. ${ }^{2}$, Babalola, O.J. ${ }^{4}$, \\ Olarewaju, S.O. ${ }^{1}$ \\ ${ }^{1}$ Department of Community Medicine, Osun State University, Osogbo, Nigeria \\ ${ }^{2}$ Department of Clinical Nursing University College Hospital, Ibadan, Nigeria \\ ${ }^{3}$ Department of Chemical Pathology Ladoke Akintola University of Technology, Osogbo, Nigeria. \\ ${ }^{4}$ Oyo state Tuberculosis and leprosy control unit. Ministry of Health. Secretariat, Ibadan, Nigeria
}

*Corresponding author: Dr Callistus Akinleye (E-mail: cakinleye.akinleye@uniosun.edu.ng)

Introduction: MDR-TB poses a significant challenge to global management of TB. Laboratories in many countries among which include Nigeria are unable to evaluate drug resistance, and clinical predictors of MDR-TB might help target suspected patients.

Method: The study was a cross sectional study design. Multistage sampling technique was employed in the selection of 403 tuberculosis patients. Data were analyzed using SPSS version 25. Level of significance was set at $\mathrm{P}<0.05$.

Results: Fifty three $53(13.2 \%)$ of the total respondent had MDR-TB compare to national prevalence of $8 \%$ which is steeper among males 36(67.9\%) $(\mathrm{p}>0.05)$. Education and Occupation shows a significant association with MDR-TB, $\left(\chi^{2}=24.640, \mathrm{p}=0.007\right)$ and $\left(\chi^{2}=14.416, \mathrm{p}=0.006\right)$ respectively, smoking $(\mathrm{r}=0.074, p<0.05)$ and alcohol consumption $(\mathrm{r}=0.083, p>0.05)$ show no significant association with occurrence MDR-TB.

Conclusion: Previous TB treatment and Adherence with treatment regimen were found to be the major risk factor for MDR-TB. Targeted educational intervention for patients and their contacts may minimize the non-adherence with prescribed TB treatment and lessen MDR-TB magnitude.

Key words: TB Patients, MDR-TB, tuberculosis, risk factors.

Research Journal of Health Sciences subscribed to terms and conditions of Open Access publication. Articles are distributed under the terms of Creative Commons Licence (CC BY-NC-ND 4.0). (http://creativecommons.org/licences/by-nc-nd/4.0).

http://dx.doi.org/10.4314/rejhs.v8i2.10 


\title{
PEER REVIEWED ABSTRACT SUBMITTED TO THE COLLEGE OF HEALTH SCIENCES, OSUN STATE UNIVERSITY ANNUAL SCIENTIFIC CONFERENCE, JUNE 15-19, 2020.
}

\author{
ABSTRACT - CHS/2020/02 \\ Factors influencing uptake of prostate cancer screening at among adult males \\ in Iseyin, Oyo State \\ *Olarewaju, S.O. ${ }^{1}$, Akinola, A.D. ${ }^{2}$, Oyekunle, E.O. ${ }^{3}$, Adeyemo C. ${ }^{4}$ \\ ${ }^{I}$ Department of Community Medicine, Osun-State University, Osogbo, Nigeria \\ ${ }^{2}$ Oyo State Hospital Health Management Board, Ibadan, Nigeria \\ ${ }^{3}$ Department of Radiology, University College Hospital, Ibadan, Nigeria \\ ${ }^{4}$ Public Health Department, Institute Superior Desante Niamey, Niger Republic
}

Corresponding Author: Dr Sunday Olarewaju (Email: sunday.olarewaju@uniosun.edu.ng)

Introduction: Prostate cancer (PCa) is the second leading cause of cancer-related death in the world. This study assessed factors influencing uptake of PCa screening at a popular town in Iseyin, Oyo State.

Methods: Relevant information was obtained from 376 participants using pre-tested semi-structured questionnaires. Respondents were selected through multistage sampling technique Statistical tests such as Chi-square, Fisher's exact test and Student's T-test were performed to duly analyse data obtained.

Results: Participants' mean age was $50.2 \pm 8.0$ years with a larger (58.5\%) proportion of men aged 50 and below. Overall summarized scores on inadequate knowledge and unfavourable attitude were $42.8 \%$ and $44.7 \%$ respectively. Specific knowledge regarding location of prostate, risk factors and symptoms was as low as $21.0 \%, 26.3 \%$ and $37.2 \%$, respectively. Barely $27.9 \%, 19.9 \%$ and $16.2 \%$ knew prostate specific antigen test, digital rectal examination and ultrasound as PC screening techniques. Previous uptake of screening was very low being $16.0 \%$. Individuals with poor knowledge and those who are nonprofessionals are 3 times (Odds Ratio - 0.295) and 2 times (Odds Ratio - 0.524) respectively less likely to do PCa screening compared with their other counterparts

Conclusion: The study showed considerable awareness of prostate cancer. However, comprehensive knowledge of its symptoms and the screening methods was greatly lacking. The need is therefore indicated for an aggressive health promotion intervention designed to increase awareness on PC screening at the community level.

Keywords: prostate cancer, uptake, screening methods

Research Journal of Health Sciences subscribed to terms and conditions of Open Access publication. Articles are distributed under the terms of Creative Commons Licence (CC BY-NC-ND 4.0). (http://creativecommons.org/licences/by-nc-nd/4.0).

http://dx.doi.org/10.4314/rejhs.v8i2.10 


\title{
PEER REVIEWED ABSTRACT SUBMITTED TO THE COLLEGE OF HEALTH SCIENCES, OSUN STATE UNIVERSITY ANNUAL SCIENTIFIC CONFERENCE, JUNE 15-19, 2020.
}

\author{
ABSTRACT - CHS/2020/03 \\ Relationship between breakfast consumption patterns and academic \\ performance of senior secondary school students (a comparative study \\ between public and private schools).
}

\author{
*Omobuwa, O., Olawale, T.E., Adepoju, I.D., Aduroja, J.O., Adeyemo, A.S. \\ Department of Community Medicine, Osun State University, Osogbo, Nigeria
}

\begin{abstract}
*Corresponding author: Dr. Omobuwa, O. (Email: olubukola.omobuwa@uniosun.edu.ng)
Introduction: Goal 2 of the SDGs targets attaining zero hunger globally. Breakfast is considered to play a crucial role in maintaining the physical health and intellectual capabilities of a person; and said to be very important for a child as it contains nutrients essential for good mental growth and learning outcomes.
\end{abstract}

\begin{abstract}
Methods: A comparative, cross-sectional study was done to determine the relationship between breakfast consumption patterns and academic performance of senior secondary school students. 494 respondents from 2 private and 2public schools participated; questionnaires were used to collect information from respondents. Data were analyzed using SPSS 23.0; appropriate univariate, bivariate and multivariate analyses were done.
\end{abstract}

Results: Participants attending private schools who usually ate breakfast had better overall academic performance (79.1\% recorded "above average" performance) compared to their public school counterparts $(62.3 \%)$; demonstrated better knowledge about breakfast (77.6\% vs $25 \%)$; and also showed better attitude towards daily breakfast consumption ( $75.9 \%$ vs $28.6 \%)$. Daily breakfast consumption rates were $74.3 \%$ and $43 \%$ respectively. Daily breakfast consumers had significantly better academic performance records in both private and public schools ( $\mathrm{p}<0.001$ in both instances), suggesting a strong association between breakfast consumption and academic performance.

Conclusion: Private school students demonstrated better knowledge, attitude and practice of daily breakfast consumption and there appeared to be a positive association between daily breakfast consumption and academic performance. We recommend that parents/guardians of secondary school students be encouraged to give their wards daily breakfast and also that school meal programmes be encouraged in secondary schools.

Keywords: breakfast consumption, academic performance, secondary education.

Research Journal of Health Sciences subscribed to terms and conditions of Open Access publication. Articles are distributed under the terms of Creative Commons Licence (CC BY-NC-ND 4.0). (http://creativecommons.org/licences/by-nc-nd/4.0).

http://dx.doi.org/10.4314/rejhs.v8i2.10 


\title{
PEER REVIEWED ABSTRACT SUBMITTED TO THE COLLEGE OF HEALTH SCIENCES, OSUN STATE UNIVERSITY ANNUAL SCIENTIFIC CONFERENCE, JUNE 15-19, 2020.
}

\section{ABSTRACT - CHS/2020/04 \\ Knowledge, perception and practices related to sexually transmitted infections among undergraduates of Osun State University.}

\author{
*Omobuwa, O., Okeowo, U.A., Olaitan, S.A., Olasinde, A.O. \\ Department Of Community Medicine, Osun State University, Osogbo, Nigeria
}

*Corresponding author: Dr. Omobuwa O (Email: olubukola.omobuwa@uniosun.edu.ng)

Introduction: STIs are considered a ravaging social and public health problem worldwide, and a big challenge to Nigeria and Africa. International data showed that $70 \%$ of people with STIs are youths. This study was conducted to assess the knowledge, perception and practices related to sexually transmitted infections (STIs) amongst of Osun State University undergraduates.

Methods: A descriptive cross-sectional study was conducted among UNIOSUN undergraduates aged 1524 years. Multistage sampling technique was employed to recruit eligible participants into the study. A pretested, self-administered questionnaire was used to collect information on respondents' sociodemographic characteristics, STI knowledge, perception, and practices. Data were analyzed using SPSS (version 23.0). Frequency tables were generated, chi-square test was used to test associations between categorical variables. Level of statistical significance was set at $p<0.05$.

Results: Mean (SD) age of respondents was $20.91( \pm 1.92)$ years. Seventy-four per cent of them were aged 20-24 years, $66.1 \%$ were female. Most (94.0\%) were aware of STIs, $82 \%$ had good knowledge; $92.0 \%$ had positive perception. Three-quarters $(75 \%)$ were sexually active, $49.4 \%$ of whom did not consistently use condoms during sexual intercourse; $14.4 \%$ had multiple sexual partners in the preceding 12 months. Good sexual practices were reported by only $52.0 \%$ of sexually active respondents.

Conclusion: Respondents' knowledge, perception and practices about STIs were fair; some had misconceptions. We recommend inclusion of STI education in the university undergraduate curriculum (General Studies); and investment in STI prevention programs to improve knowledge hence reducing infection rates among undergraduates.

Keywords: Knowledge, perception, practices, sexually transmitted infections, undergraduates

Research Journal of Health Sciences subscribed to terms and conditions of Open Access publication. Articles are distributed under the terms of Creative Commons Licence (CC BY-NC-ND 4.0). (http://creativecommons.org/licences/by-nc-nd/4.0).

http://dx.doi.org/10.4314/rejhs.v8i2.10 


\title{
PEER REVIEWED ABSTRACT SUBMITTED TO THE COLLEGE OF HEALTH SCIENCES, OSUN STATE UNIVERSITY ANNUAL SCIENTIFIC CONFERENCE, JUNE 15-19, 2020.
}

\author{
ABSTRACT - CHS/2020/05 \\ Assessment of the effects of cocoa powder on blood pressure in humans - a \\ preliminary study in Osogbo, Nigeria. \\ *Alebiosu, C.O. ${ }^{1}$, Omobuwa, O. ${ }^{2}$, Akintunde, A.A. ${ }^{3}$, Peter, J.O. ${ }^{3}$, Olayinka, A. ${ }^{4}$ \\ 'Department of Medicine, College of Health Sciences, Osun State University, Osogbo, Nigeria \\ ${ }^{2}$ Department of Community Medicine, College of Health Sciences, Osun State University, Osogbo, Nigeria \\ ${ }^{3}$ Department of Medicine, Faculty of Clinical Sciences, College of Health Sciences, Ladoke Akintola University \\ of Technology, Osogbo, Nigeria. \\ ${ }^{4}$ Chemical Pathology Laboratory, College of Health Sciences, Osun State University, Osogbo, Nigeria
}

Corresponding Author: Alebiosu, C.O.(Email: olutayo.alebiosu@uniosun.edu.ng)

Introduction: Cocoa powder contains polyphenols (phytonutrients), which are increasingly being used either as dietary supplements or in fortification of foods. Polyphenols exhibit antioxidant activity known to play a vital role in reducing the risk of some diseases (including cardiovascular diseases) in humans by protecting cells in the body from damage during aerobic production of energy.

Methods: Sixty-eight patients attending cardiology clinics (for treatment of hypertension) in two selected hospitals in Osogbo were serially recruited into the study. A control group without cocoa flavanoid supplement was recruited. Physical examination was conducted on them, demographic and clinical parameters were recorded. Each participant was instructed to consume $25 \mathrm{~g}$ of cocoa powder diluted in 250 $\mathrm{ml}$ of water twice daily. Physical examination were repeated forthnightly, BMI was also calculated on each visit. They were followed up for eight weeks and relevant clinical parameters were repeated at each visit.

Results: During clinic visits, the proportion of hypertensive BP status gradually declined over the weeks as follows: $19(28.4 \%), 16(25.4 \%), 8(13.3 \%)$ and 7 (11.6) in weeks $1,3,5$ and 7 respectively. The BMI of the subjects did not show any significant variation over the weeks during the course of the study.

Conclusion: The study showed that daily cocoa consumption might be beneficial in the control of blood pressure control and complimentary to pharmacotherapy in hypertensive Nigerian patients. However, we recommend the conduct of further randomized large scale in the Nigerian population in order to further validate the findings of this study.

Keywords: Cocoa flavanoid, blood pressure, humans, preliminary study.

Research Journal of Health Sciences subscribed to terms and conditions of Open Access publication. Articles are distributed under the terms of Creative Commons Licence (CC BY-NC-ND 4.0). (http://creativecommons.org/licences/by-nc-nd/4.0).

http://dx.doi.org/10.4314/rejhs.v8i2.10

Res. J. of Health Sci. Vol 8(2), April/June 2020 


\title{
PEER REVIEWED ABSTRACT SUBMITTED TO THE COLLEGE OF HEALTH SCIENCES, OSUN STATE UNIVERSITY ANNUAL SCIENTIFIC CONFERENCE, JUNE 15-19, 2020.
}

\author{
ABSTRACT - CHS/2020/06 \\ Insilico anti-malaria activity of quinolone compounds against Plasmodium \\ Falciparum dihydrofolate reductase (pfDHFR) \\ Balogun, T.A., Omoboyowa, D.A. \\ Department of Biochemistry, Adekunle Ajasin University, Akungba-Akoko, Nigeria.
}

Corresponding author: Balogun, T.A.

Introduction: Chemotherapy remains the kernel of malaria control and the available anti-malarial drugs are not only expensive but also parade heterogeneous levels of toxicity and may invoke poor compliance in patients. Investigation of anti-malarial potentials of plants used in traditional therapy of malaria has been one of the means of searching for new anti-malarial drugs that will liberate human race from the burden of this life threatening disease. The present study focuses on the screening of quinolone compounds against Plasmodium falciparum dihydrofolate reductase (pfDHFR) for anti-malarial potential using Glide (Schrodinger maestro 2017-1).

Methods: Computational tool using Glide (Shrondinger 2017-1) was employed to investigate the therapeutic relevance of six (6) quinolone derivatives retrieved from PUBCHEM via molecular docking against pfDHFR downloaded from protein data base.

Results: The result showed that, lascufloxacin and moxifloxacin bind with higher affinity and lower free energy with catalytic domain of pfDHFR having glide score of -6.597 and -5.653 respectively compared to standard ligand (quinine) with glide score of -3.728. Lascufloxacin interact with amino acid residue of the catalytic domain (SER 511, ARG 510, GLU 382) as evaluated by energy decomposition per residue lascufloxacin-pfDHFR complex.

Conclusion: The quinolone derivatives investigated in this study can be consider as potential inhibitors of pfDHFR therefore give new perception to their use as anti-malarial agent.

Keywords: Quinolone, dihydrofolate reductase, molecular docking, lascufloxacine, malaria

Research Journal of Health Sciences subscribed to terms and conditions of Open Access publication. Articles are distributed under the terms of Creative Commons Licence (CC BY-NC-ND 4.0). (http://creativecommons.org/licences/by-nc-nd/4.0).

http://dx.doi.org/10.4314/rejhs.v8i2.10 


\title{
PEER REVIEWED ABSTRACT SUBMITTED TO THE COLLEGE OF HEALTH SCIENCES, OSUN STATE UNIVERSITY ANNUAL SCIENTIFIC CONFERENCE, JUNE 15-19, 2020.
}

\section{ABSTRACT - CHS/2020/07 \\ Influence of family functionality and family structure on immunization status of infants attending the general outpatient clinic in a Nigerian medical centre}

\author{
*Bolaji, A.I. ${ }^{1}$, Ojebode, T.O. ${ }^{2}$, Adekanye, O.S. ${ }^{3}$, Bolaji, A.O. ${ }^{4}$ \\ ${ }^{\prime}$ Directorate of Health Services, Bowen University. Iwo, Nigeria \\ ${ }^{2}$ Department of Family Medicine, Baptist Medical Center, Saki, Nigeria \\ ${ }^{3}$ Department of Family Medicine Baptist Medical Center, Saki, Nigeria \\ ${ }^{4}$ Eleta Eye Institute, Ibadan, Nigeria
}

"Corresponding author: Bolaji, A.I. (E mail: adetola.bolaji@bowen.edu.ng)

Introduction: Vaccine preventable deaths remain endemic and contribute significantly to childhood morbidity in Nigeria and it has been recognized that good family structure improves the children well being, health and eating habit, however the contribution of family structure and functionality on immunization status is not yet ascertained. The purpose of this study are to determine the level of immunization status among the respondents, assess their knowledge on immunization and determine the influence of family structure and functionality on the immunization status.

Methods: A cross-sectional descriptive study was conducted in 2016 in the GOPC of Baptist Medical Centre, Saki, Oyo State. Family APGAR Scale and self-design questionnaire were used to collect data from 299 respondents using systematic sampling technique. A SPSS (version 21) was used for the analysis.

Results: The results revealed that majority $(82.9 \%)$ of the respondents were fully immunized and $98 \%$ had knowledge about Immunization. Majority of the respondents $(85.6 \%)$ were from functional families. Family functionality was statistically significant on the immunization status $\left(\mathrm{X}^{2}=101.694, \mathrm{P}=0.000\right)$ as well as some components of family structure: family type $(\mathrm{P}=0.000)$, family size $(\mathrm{P}=0.000)$, ethnic group $(\mathrm{P}=0.000)$, and number of children $(\mathrm{P}=0.000)$

Conclusion: The respondents had adequate knowledge about immunization. Also, Family functionality and family structure influence the immunization status of the infants. Therefore, more studies should be conducted on the influence of family functionality and family structure on immunization status using multicenter approach.

Keywords: Immunization, family, functionality, structure, vaccine 